\title{
A study of knowledge and awareness on polycystic ovarian syndrome among nursing students in a tertiary centre in South India
}

\author{
R Sasikala, Deepa Shanmugham, Jessy Varghese, Deepak Kannan Saravanan \\ Corresponding author: Dr. Deepa Shanmugham, B-12, Staff Quarters, Aravind Eye Hospital, \\ Thavalakuppam, Pondicherry - 605007, India; Email : drdeepabalamurugan@gmail.com
}

Distributed under Attribution-Non Commercial - Share Alike 4.0 International (CC BY-NC-SA 4.0)

\section{ABSTRACT}

\begin{abstract}
Objectives: This study was conducted to evaluate the knowledge and awareness on PCOS among nursing students. Methodology: This was a questionnaire based cross sectional study conducted in the Department of Obstetrics and Gynaecology in a Tertiary Care Centre among the nursing students. A pre-designed, pre-tested, semi-structured 15 items questionnaire containing 3 components: knowledge about risk factors (6), clinical symptoms \& signs (4) and complications (5) of PCOS was used for online data collection and the results were analysed. Results: Around 88 students participated in the study. Majority of the students $(89.8 \%)$ claimed polycystic ovarian syndrome (PCOS) to be the most common endocrinological problem. Regarding the knowledge about the risk factors, 83 students were aware of obesity as the risk factor. In view of knowledge on long term complications, 62 students $(70.45 \%)$ were aware about metabolic syndrome, 51 students (57.95\%) about hypertension, 50 participants $(56.81 \%)$ about being prone for diabetes mellitus, 60 students $(68.18 \%)$ about risk of endometrial cancer. Conclusion: Even though the nursing students had knowledge regarding the risk factors associated with PCOS, their awareness about the complications of PCOS is significantly less. Effective educational intervention conducted especially for nurses can significantly increase their level of knowledge on PCOS.
\end{abstract}

Keywords: PCOS, questionnaire, risk, complication.

Polycystic ovarian syndrome (PCOS) is an endocrine disorder which commonly affects the adolescent girls. It affects $5 \%$ to $10 \%$ of women in their reproductive years ${ }^{1}$. PCOS has a wide range of presentation in adolescents as menstrual irregularity, hirsutism, acne and acanthosis nigricans. It is important to make an early diagnosis in order to prevent early and late sequel of the syndrome. ${ }^{2}$ The pathophysiology responsible for the development of polycystic ovaries has puzzled gynaecologists and endocrinologists for many years and has proven very difficult to define ${ }^{3}$. However, the main pathogenesis still could be hormonal imbalance and insulin resistance. PCOS is associated with increased metabolic and cardio-vascular risk factors due to increased insulin resistance. ${ }^{4}$ In more than $40 \%$ of cases, PCOS is associated with obesity, as well as impaired glucose tolerance, type 2 diabetes, and the metabolic syndrome ${ }^{5}$. India has witnessed about $30 \%$ rise in PCOS cases in the last couple of years. Lack of knowledge and lifestyle changes are considered to be the major factor leading to rapid increase in incidence of PCOS in recent years, resulting in complications. Awareness of PCOS symptoms and complications among the health care workers is essential for early treatment and to prevent serious complications. The gap in the level of knowledge and perception when assessed among nurses can be used as a tool to improve the education of the public on PCOS. This study

Received: $12^{\text {th }}$ July 2020, Peer review completed: $27^{\text {th }}$ August 2020, Accepted: $7^{\text {th }}$ September 2020.

Sasikala R, Shanmugham D, Varghese J, Saravanan DK. A study of knowledge and awareness on polycystic ovarian syndrome among nursing students in a tertiary centre in South India. The New Indian Journal of OBGYN. 2021; 8(1): 121-25. 
was conducted to evaluate the knowledge and awareness on PCOS among nursing students in a tertiary centre in South

India.

\section{Methodology}

This is a questionnaire based cross sectional study conducted in the department of obstetrics and gynaecology in a tertiary care centre from March 2020 to May 2020. The survey was conducted among the nursing students by consecutive sampling after informed and written consent. A pre-designed, pre-tested, semi-structured 15 items questionnaire containing 3 components: knowledge about risk factors [obesity, sedentary life style, lack of physical exercise, junk food intake, familial inheritance (6)], clinical symptoms \& signs [menstrual irregularities, hirsutism, acanthosis nigricans, infertility- (4)] and complications [metabolic syndrome, dyslipidaemia and coronary artery disease, endometrial cancer, diabetes mellitus, psychological upset - (5)] of PCOS was used for online data collection.

The data collected were analysed through descriptive analysis as frequencies and percentages after entry into microsoft excel sheets. Chi square test was used to test the association between different variables. $\mathrm{P}$ value $<0.05$ was considered significant.

\section{Results}

Among 95 participants, 88 students responded to the online questionnaire. The study group belonged to age group of 18-22 years, mean age being 21.4 years. Majority of the students belonged to middle socio- economic status and from rural areas. Majority of the students $(89.8 \%)$ claimed PCOS to be the most common endocrinological problem in reproductive age group.

The knowledge about the risk factors for PCOS is illustrated in table 1. Regarding the knowledge about the risk factors, 83 students were aware of obesity as the risk factor, 73 participants knew that sedentary life style and lack of physical exercise can increase the risk for PCOS.70\% of the students accepted that junk food intake is associated with PCOS. Only half of the participants had the knowledge about familial inheritance of PCOS. Table 2 depicts the knowledge about clinical presentation of PCOS. On analysing the awareness about the clinical presentation, $85 \%$ responded as menstrual irregularities, half of them had knowledge about hirsutism (abnormal male type of hair distribution) and acanthosis nigricans (velvety patches over nape of the neck)
Table 1: Knowledge regarding risk factors for PCOS

\begin{tabular}{ll}
$\begin{array}{l}\text { Yes }(\mathbf{n}=\mathbf{8 8}) \\
\text { No. }(\%)\end{array}$ & $\begin{array}{l}\text { No }(\mathbf{n}=\mathbf{8 8}) \\
\text { No. }(\%)\end{array}$ \\
$83(94.31 \%)$ & $5(5.68 \%)$ \\
$55(62.5 \%)$ & $33(37.5 \%)$ \\
& \\
$73(82.95 \%)$ & $15(17.05 \%)$ \\
$62(70.45 \%)$ & $26(29.55 \%)$ \\
$53(60.22)$ & $35(39.78 \%)$ \\
\hline
\end{tabular}

(56.81\% and $61.36 \%$ respectively). Interestingly, majority of them $(84.09 \%)$ knew that PCOS can cause infertility.

Knowledge about the long-term complications associated with PCOS among the study participants is shown in table 3. In view of knowledge on long term complications, 62 students $(70.45 \%)$ were aware about metabolic syndrome, 59 students $(67.04 \%)$ about dyslipidaemia and risk for coronary artery disease, 51 students $(57.95 \%)$ about hypertension, 50 participants (56.81\%) about being prone for diabetes mellitus, 60 students $(68.18 \%)$ about risk of endometrial cancer. However almost all of them knew that the life style modification is the first line of management in PCOS.

Table 2: Knowledge about clinical presentation of PCOS

\begin{tabular}{lll}
\hline Questions & $\begin{array}{l}\text { Yes (n=88) } \\
\text { No. (\%) }\end{array}$ & $\begin{array}{l}\text { No (n=88) } \\
\text { No. (\%) }\end{array}$ \\
\hline $\begin{array}{l}\text { Menstrual abnormalities } \\
\begin{array}{l}\text { Abnormal male type of hair } \\
\text { distribution (hirsutism) }\end{array}\end{array}$ & $75(85.22 \%)$ & $13(14.78 \%)$ \\
$\begin{array}{l}\text { Infertility } \\
\begin{array}{l}\text { Velvety patches over nape of neck } \\
\text { (acanthosis nigricans) suggestive }\end{array}\end{array}$ & $\begin{array}{l}50(56.81 \%) \\
\text { of insulin resistance in PCOS }\end{array}$ & $\begin{array}{l}38(44.09 \%) \\
14(15.91 \%)\end{array}$ \\
\hline
\end{tabular}

Chi square test was used to test the association between known demographic characteristics like age, sex, educational level and knowledge and awareness about PCOS. Younger the nurse, lower the knowledge level on PCOS $(p=0.04)$. Third year nursing students had more knowledge on risk factors and complication compared to first year students which was statistically significant $(p<0.001)$. Similarly female students had more knowledge and awareness on PCOS compared to male nursing students $(\mathrm{p}<0.01)$.

Table 3: Awareness about complications due to PCOS

\begin{tabular}{lll}
\hline Questions & $\begin{array}{l}\text { Yes (n=88) } \\
\text { No. (\%) }\end{array}$ & $\begin{array}{l}\text { No (n=88) } \\
\text { No. (\%) }\end{array}$ \\
\hline $\begin{array}{l}\text { PCOS left untreated can lead to } \\
\text { metabolic syndrome }\end{array}$ & $62(70.45 \%)$ & $26(29.55 \%)$ \\
$\begin{array}{l}\text { PCOS can lead to endometrial cancer } \\
\begin{array}{l}\text { PCOS patients are prone to become } \\
\text { diabetic }\end{array}\end{array}$ & $50(68.18 \%)$ & $28(31.82 \%)$ \\
$\begin{array}{l}\text { PCOS can cause psychological upset } \\
\text { PCOS can cause dyslipidemia and is a }\end{array}$ & $74(56.81 \%)$ & $36(43.19 \%)$ \\
$\begin{array}{l}\text { risk factor for coronary artery disease } \\
\text { PCOS if left untreated can cause }\end{array}$ & $59(67.04 \%)$ & $14(15.91 \%)$ \\
$\begin{array}{l}\text { hypertension } \\
\begin{array}{l}\text { In PCOS the first line of management } \\
\text { is life style modification }\end{array}\end{array}$ & $51(57.95 \%)$ & $37(42.96 \%)$ \\
& $71(80.68 \%)$ & $17(29.32 \%)$ \\
\hline
\end{tabular}




\section{Discussion}

Polycystic ovarian syndrome (PCOS) is a heterogeneous, chronic endocrine disorder commonly diagnosed in women of reproductive age. PCOS increases the risk for various dermatologic, oncologic, metabolic, reproductive, and psychological aberrations. In 1935, Stein IF et al first described a symptom complex associated with anovulation. ${ }^{6}$ They described seven patients with amenorrhea, hirsutism and enlarged polycystic ovaries. They reported that all seven resumed menses and that two became pregnant after bilateral wedge resection of ovaries. The knowledge about the risk factors, presentation and complication of PCOS among para medical workers and students is of paramount importance to educate the community.

A study conducted in Hoshangabad, India to test the effectiveness of the of education programme on their knowledge on PCOS revealed a positive correlation between education and level of knowledge ${ }^{7}$ (Gupta et al, 2017). Sunanda B et al found that $76 \%$ of the samples were with average knowledge and $10.7 \%$ with good knowledge regarding polycystic ovarian syndrome ${ }^{8}$. Sills ES et al found that more than $97 \%(n=638)$ of the respondents were familiar with PCOS, while $1.9 \%$ had not been told about PCOS, and $<1 \%$, told that they are uncertain. ${ }^{9}$

The awareness among our study participants about obesity as the risk factor was as high as $94.31 \%$, similar to other study done by Alessa et al. ${ }^{10}$ This result is promising in terms of prevention of future increase in the incidence of PCOS among adolescent girls. More than $40 \%$ of women with PCOS are obese ${ }^{11}$. There is an increasing awareness of PCOS among the adolescent population along with an increase in diagnosis and an increased incidence of established co-morbidities such as obesity and type 2 diabetes.

Majority of our study people were aware of PCOS and the symptoms associated. In a study by Alessa et al. among aware females, most women were aware of associated symptoms, as irregular menstrual cycle, facial acne, hirsutism, reduce fertility, weight gain, abortion, pelvic pain $^{10}$. In a study by Haq et al, 407(90.2\%) subjects were having adequate knowledge about PCOS after educational intervention. ${ }^{12}$ Similar results were observed in a study by Mohammed et $\mathrm{al}^{13}$.

In a study by Jena et al among adolescent girls, of 965 patients, only $27(2.79 \%)$ were aware of an entity called PCOS. Majority $(70 \%)$ were aware that diet restriction and exercise were the primary modalities of treatment, whereas, only $3.7 \%$ knew about the role of contraceptive pills in $\mathrm{PCOS}^{14}$. Rao et al found in their study that majority of participants ranked their PCOS knowledge as "Know some" or less $\left(66.3 \%\right.$ women and $83 \%$ of men). ${ }^{15}$ Upadyay in his study among medical students concluded that $72 \%$ of participants were aware of PCOS while $28 \%$ were unaware of $\operatorname{PCOS}^{16}$.

In the present study, most participants were aware of menstrual abnormalities and infertility as common clinical presentation. Similarly, irregular menstrual cycle was the most commonly reported clinical feature in a study by Piltonen et al, followed by obesity and infertility ${ }^{17}$. The most commonly reported comorbidities were reduced fertility, type 2 diabetes, gestational diabetes, insulin resistance, and cardiovascular disease risk factors. ${ }^{17}$ Insulin resistance being a common feature associated with this condition led to the conclusion that, there is a causal relationship between metabolic disorders and $\operatorname{PCOS}^{18}$.

PCOS increases the risk to metabolic disorder which is the leading cause of diabetes and cardiovascular disease. In our study, only half of the study participants had knowledge about diabetes mellitus and hypertension as a long-term complication of PCOS, which needs educational intervention. Surprisingly, $70 \%$ of them were aware of the term metabolic syndrome as a complication of untreated PCOS. Alessa et al in their study found that many participants were aware of complications related to PCOS like breast and uterus cancer, hyperandrogenaemia, anxiety and psychological disturbance ${ }^{10}$. However, in a study by Patel and Rai, $46 \%$ of the people did not know about the role of lifestyle changes like diet, lack of physical activities, stress and obesity that are involved in the pathogenesis of the disorder. ${ }^{19}$ Case studies have shown that women with PCOS are anxious, depressed and have eating and bipolar disorders. The depression is most likely to occur in the teenage girls because of consciousness of their physique ${ }^{20}$. In our study, majority of the participants $(84.09 \%)$ agreed that PCOS can cause psychological upset.

In another study conducted in the United States of America amongst physicians, one third of the respondents in the study did not know the diagnostic criteria they used in diagnosing the condition. They were also unaware of the cardio metabolic comorbidities associated with the condition; however the psychological complications such as depression, anxiety and low quality of life were mentioned ${ }^{21}$. A combination of hyper insulinemia, hyperandrogenism, and oligo-anovulation increases the risk of endometrial cancer 
and other endometrial disorders. ${ }^{22}$ Long term complications such as pre-eclampsia, gestational diabetes are found in women with PCOS. Their unborn children suffer complications such as fetal macrosomia, small for gestational age and perinatal mortality.

\section{Conclusion}

Even though the nursing students had knowledge regarding the risk factors associated with PCOS, their awareness about the complications of PCOS is significantly less. Effective educational intervention conducted especially for nurses can significantly increase their level of knowledge on PCOS.

\section{Conflict of interest: None. Disclaimer: Nil.}

\section{References}

1. Avery JC, Braunack-Mayer AJ. The information needs of women diagnosed with polycystic ovarian syndrome Implications for treatment and health outcomes. BMC Womens Health. 2007; 7: 9

2. Franks S. Polycystic ovary syndrome. N Engl J Med. 1995; 333(13): 853-61.

3. Shanmugham D, Vidhya Lakshmi RK, Shivamurthy HM. The effect of baseline serum luteinizing hormone levels on follicular development, ovulation, conception and pregnancy outcome in infertile patients with polycystic ovarian syndrome. Int $\mathrm{J}$ Reprod Contracept Obstet Gynecol. 2018; 7: 318- 22.

4. Shanmugham D, Natarajan S, karthik A. Prevalence of thyroid dysfunction in patients with polycystic ovarian syndrome: a cross sectional study. Int $\mathrm{J}$ Reprod Contracept Obstet Gynecol. 2018; 7: 3055-9.

5. Broder-Fingert S, Shah B, Kessler M, Pawelczak M, David R. Evaluation of adolescents for polycystic ovary syndrome in an urban population. J Clin Res Pediatr Endocrinol. 2009;1(4):188-93.

6. Stein IF, Leventhal ML. Amenorrhea associated with bilateral polycystic ovaries. Am J Obstet Gynecol. 1935; 29:181-91

7. Gupta M, Singh D, Toppo M, Priya A, Sethia S, Gupta P. A cross sectional study of polycystic ovarian syndrome among young women in Bhopal, Central India. International Journal of Community Medicine and Public Health. 2017; 5(1): 95.
8. Sunanda B, Nayak S. A study to assess the knowledge regarding PCOS (polycystic ovarian syndrome) among nursing students at NUINS. NUJHS. 2016; 6(3): 2.

9. Sills ES, Perloe M, Tucker MJ, Kaplan CR, Genton MG, Schattman GL. Diagnostic and treatment characteristics of polycystic ovary syndrome: descriptive measurements of patient perception and awareness from 657 confidential self-reports. BMC Women's Health. 2001;1(1): 3

10. Alessa A, Aleid D, Almutairi S, Alghamdi R, Huaidi N, Almansour E, et al. Awareness of polycystic ovarian syndrome among Saudi females. International Journal of Medical Science and Public Health. 2017; 6 (6): $1013-9$.

11. Sam S. Obesity and Polycystic Ovarian Syndrome. Obesity Management. 2017; 3(2): 69-73.

12. Haq NU, Khan Z, Riaz S, Nasim A, Shahwani R, Tahir M. Prevalence and Knowledge of Polycystic Ovary Syndrome (PCOS) Among Female Science Students of Different Public Universities of Quetta, Pakistan. Imperial Journal of Interdisciplinary Research (IJIR). 2017; 3(6): 385 - 92.

13. Mohamed HAA. Effect of educational program on the level of knowledge regarding polycystic ovarian syndrome among adolescent girls. Journal of Nursing Education and Practice. 2016; 6(10): 80

14. Jena SK, Mishra L, Naik SS, Khan S. Awareness and opinion about polycystic ovarian syndrome (PCOS) among young women: a developing country perspective. International Journal of Adolescent Medicine and Health. 2020; Ahead of print. Doi. https://doi.org/10.1515/ijamh-2018-0166

15. Rao M, Broughton KS, LeMieux MJ. Cross-sectional Study on the Knowledge and Prevalence of PCOS at a Multi-ethnic University. PROGREVMED. 2020; 5: e0028

16. Upadhye JJ, Shembekar CA. Awareness of PCOS (polycystic ovarian syndrome) in adolescent and young girls. International Journal of Reproduction Contraception, Obstetrics and Gynecology. 2017; 6(6): 2297-2301.

17. Piltonen TT, Ruokojarvi M, Karro H, Kujanpaa L, Morin-Papunen L, Tapanainen JS, et al. Awareness of polycystic ovary syndrome among obstetriciangynecologists and endocrinologists in Northern Europe. PLoS ONE. 2019; 14 (12): e022607 
The New Indian Journal of OBGYN. 2021 (July-December);8(1)

18. Setji TL, Brown AJ. Polycystic Ovary Syndrome: Diagnosis and Treatment. The American Journal of Medicine. 2007;120(2): 128-32.

19. Patel J, Rai S. Polycystic ovarian syndrome (PCOS) awareness among young women of central India. Int $\mathrm{J}$ Reprod Contracept Obstet Gynecol. 2018; 7: 3960-4.

20. Sirmans SM, Pate KA. Epidemiology, diagnosis and management of polycystic ovaries. Clin Epidemiol. 2014; 6: 1-13.

21. Dokras A, Saini S, Gibson-Helm M, Schulkin J, Cooney L, Teede H. Gaps in knowledge among physicians regarding diagnostic criteria and management of polycystic ovary syndrome. Fertility and Sterility. 2017; 107(6): 1380-6.
22. Palomba S, Santagni S, Falbo A, La Sala GB. Complications and challenges associated with polycystic ovary syndrome: Current perspectives. International Journal of Women's Health. 2015; 7: 745-63.

R Sasikala ${ }^{1}$, Deepa Shanmugham ${ }^{2}$, Jessy Varghese ${ }^{3}$, Deepak Kannan Saravanan ${ }^{4}$

${ }^{1}$ Professor and HOD, Department of Obstetrics \& Gynaecology, Aarupadai Veedu Medical College, Pondicherry, India; ${ }^{2}$ Professor, Department of Obstetrics \& Gynaecology, Aarupadai Veedu Medical College, Pondicherry, India; ${ }^{3}$ Associate Professor, Department of Obstetrics \& Gynaecology, Aarupadai Veedu Medical College, Pondicherry, India; ${ }^{4}$ Intern, Aarupadai Veedu Medical College, Pondicherry, India. 